\title{
Role of authentic leadership and personal mastery in predicting employee creative behavior: a self-determination perspective
}

\author{
Adnan Fateh ${ }^{1}$, Norizah Mustamil ${ }^{1^{*}}$ (D) and Fakhar Shahzad ${ }^{2}$
}

\author{
*Correspondence: norizahmm@um. \\ edu.my \\ ${ }^{1}$ University of Malaya, Kuala Lumpur, \\ Malaysia \\ Full list of author information is \\ available at the end of the article
}

\begin{abstract}
Personality dispositions and their role in inducing employee creative behavior are well documented in the literature. However, much is unexplored about the collective and relative contribution of personality orientations and environmental factors in explaining creative behavior. This study used a framework based on selfdetermination theory (SDT) to measure the combined and relative contribution of personal mastery orientation and authentic leadership in predicting employee creative behavior as mediated by autonomous motivation. A self-reported survey was conducted among software developers working in software houses. The results of the study show that both personal mastery and authentic leadership are significant predictors of employee creative behavior. In addition, autonomous motivation significantly mediates the relationship between personal mastery, authentic leadership, and creative behavior. The findings of the study lend support to the combined effect of personality orientation and environmental factors in predicting employee creative behavior and test the SDT framework's efficacy in predicting creative behavior.

Keywords: Authentic leadership, Autonomous motivation, Employee creative behavior, Personal mastery, Self-determination theory
\end{abstract}

\section{Introduction}

One of the most crucial resources for modern-day organizations is the ability to think creatively (Florida 2010). Creativity ensures that organizations not only gain competitive advantage but also maintain it over time (Anderson et al. 2004). The source of creativity for an organization is its employees (Tan and Leewongcharoen 2005), because human resource is the critical differentiator between a successful organization and a failed one. The ability to generate new ideas and find novel solutions to ever-emerging problems is what makes the human resources of any organization unique, in comparison with other material resources.

Creativity is the process or the ability to generate novel and useful ideas regarding products, services, processes, or procedures (Amabile 1988). The important question is how to facilitate employee creativity that can enhance organizational competitiveness.

(c) The Author(s). 2021 Open Access This article is licensed under a Creative Commons Attribution 4.0 International License, which permits use, sharing, adaptation, distribution and reproduction in any medium or format, as long as you give appropriate credit to the original author(s) and the source, provide a link to the Creative Commons licence, and indicate if changes were made. The images or other third party material in this article are included in the article's Creative Commons licence, unless indicated otherwise in a credit line to the material. If material is not included in the article's Creative Commons licence and your intended use is not permitted by statutory regulation or exceeds the permitted use, you will need to obtain permission directly from the copyright holder. To view a copy of this licence, visit http://creativecommons.org/licenses/by/4.0/. 
For a long time, creativity was thought of as a personality attribute or a personal characteristic. A plethora of studies have focused on creative personality, the Big Five personality types, and intelligence level as predictors of creative behavior (Batey and Furnham 2006; Hornberg and Reiter-Palmon 2017; Selby et al. 2005). However, other individual factors, such as motivational traits and their relationship with creativity, have received little attention in this respect. Motivational traits are stable personality dispositions that are consistent across time and situations, and have consequences in terms of performance (Rodríguez-Cifuentes et al. 2020). Personal mastery (PM) is such a motivational trait and a non-ability personal factor that has motivational consequences for skill acquisition and performance (Kanfer and Ackerman 2000). We see PM orientation as a potential predictor of creativity because of its implications on employee selfregulation regarding skill and knowledge acquisition. However, research has shown that personality traits and individual differences alone are not strong predictors of creative performance; instead, they require a force that can push an individual to exhibit creativity (Hammond et al. 2011). Another important factor to consider in this aspect is that individual differences or personality traits cannot be easily manipulated and do not offer much control (Amabile 1996). Therefore, additional environmental factors must be considered when explaining employee creative behavior.

Unlike personality traits, the environment of an individual or an employee can be manipulated with relative ease, and its effects on creative performance can be immediately observed (Amabile 1983). Factors that are not a part of the individual, such as organizational environment, job characteristics, and leadership's attitude, also influence employee creative behavior (Anderson et al. 2014). Among environmental factors, leadership is of predominant importance. Previous research has studied the relationship between creativity and different types of leadership styles such as transformational leadership (Afsar and Umrani 2020), servant leadership (Yang et al. 2017), and ethical leadership (Shafique et al. 2019). Authentic leadership (AL) is a novel leadership style that instills trust, hope, resilience, and confidence (resources associated with employee creativity) among followers (Avolio and Fred 2014). AL is a leadership construct under development, and studies linking creativity with AL are scant; especially little is known about the underlying mechanisms through which $\mathrm{AL}$ influences creative behavior (Chaudhary and Panda 2018). The above discussion provides a rationale for studying AL in combination with PM as predictors of employee creative behavior. Therefore, we aim to address the gap in the literature by investigating the mechanism through which these proposed predictors influence employee creative behavior.

We explore motivation as a process variable between the proposed predictors and employee creative behavior, as motivation is the main driver for creativity (Amabile and Pratt 2016). Literature suggests that the primary mechanism for creativity is intrinsic motivation; however, some studies have linked extrinsic motivation with creativity as well (Gerhart and Fang 2015). To the best of our knowledge, no study has investigated the combined effects of intrinsic and extrinsic motivation on employee creativity. We address this gap by using a unique type of motivation called autonomous motivation (AM) that has elements of extrinsic and intrinsic motivation (Gagné et al. 2015) as the mechanism for employee creative performance. Additionally, the leadership of an organization is the most important environmental factor which has an unmatched impact on organizational innovation and creativity. 
In summary, this study investigates the combined and relative effects of PM orientation and AL through the mediating mechanism of AM. Self-determination theory (SDT; Deci and Ryan 1985) provides a foundation for this study. Based on the assumptions of SDT, the findings of this study will enrich the workplace creativity literature and try to unravel a unique mechanism through which creativity can be enhanced, thereby integrating and providing empirical support for both creativity theory and SDT.

\section{Theoretical background and hypothesis}

A multitude of empirical research on employee creative performance have studied creativity, divided between two polarities of motivation: intrinsic or extrinsic. The argument that creativity originates from within, and external motivation is detrimental to individual creativity, can be traced back to the cognitive evaluation theory (Ryan 1982) and to the componential model of creativity itself (Amabile 1983). Extrinsic motivation, such as financial rewards, was always considered bad for inducing creative performance. Extrinsic motivation was considered "pale and impoverished" in comparison with intrinsic motivation (Ryan and Deci 2000). However, a parallel stream of research has observed positive effects of extrinsic motivation (Eisenberger and Rhoades 2001; Eisenberger and Shanock 2003). Recently, Amabile and Pratt (2016) update the original theory of creativity and call for the incorporation of the synergetic effects of extrinsic and intrinsic motivation in the creativity framework. They posit that when extrinsic motivation is appropriately provided in combination with intrinsic motivation, it can enhance creative performance. Therefore, an understanding of different types of motivation is necessary for studying employee creative performance. SDT provides a detailed description of motivation types, ranging from intrinsic to extrinsic, and further considers the internalization of extrinsic motivation. It postulates that extrinsic motivation, when internalized, can perform in a way that is similar to intrinsic motivation.

SDT is a general theory of human development, personality, motivation, and wellbeing (Ryan et al. 2019). It lays out a broad framework for the study of human behavior (Ryan and Deci 2019). Its central assumption is that every individual has three basic psychological needs: need for autonomy, need for competence, and need for relatedness. When all these three basic psychological needs are fulfilled, an individual becomes autonomously motivated and then can act with volition and autonomy. Thwarting of basic psychological needs results in control motivation (Ryan and Deci 2000), and when an individual is autonomously motivated, internalization of extrinsic motivation occurs. High-quality tasks such as creativity, which was previously thought to be undermined by extrinsic motivation, can be induced via well-internalized extrinsic motivation. Under SDT research, need satisfaction has been studied in relation to contextual factors; however, factors intrinsic to the individual are equally important, and their effects on need satisfaction are worth exploring (Brown and Ryan 2015).

\section{Authentic leadership (AL)}

AL draws its strength from positive psychological capital, moral values, concern for followers, transparency, and ethical decision making (Walumbwa et al. 2008). AL is the "root construct" of leadership that serves as a base for other positive leadership styles that promote genuine and sustainable performance (Avolio and Gardner 2005). Previously, AL has been studied in relation to creative performance (e.g., Černe et al. 2013; Rego et al. 2014). However, studies on AL's relationship with creative performance 
from the perspective of SDT are rare. An authentic leader arouses positive affect among his or her followers and does not shy away from listening to their ideas (Banks et al. 2016).

Furthermore, authentic leaders present their original selves and authenticity to their followers and expect them to do the same (Avolio et al. 2009). Authenticity implies genuineness or originality (Lehman et al. 2018). Similarly, creativity requires novelty so that an idea can be considered creative in the first place. The definitional part of creativity, novelty, is the degree to which the idea is original (Puccio and Cabra 2012). Therefore, for an idea to be creative, it must be authentic and original. Authentic leaders present their original selves and want their followers to reciprocate; as a result, their actions are reverberated by the followers (Gardner et al. 2005).

Creativity is a challenging endeavor that involves risk-taking and moving out of one's comfort zone (Hammond et al. 2011; Shen et al. 2018). These require not only a supportive environment but also continuous support from leadership. Leaders who are supportive and make their followers feel comfortable without feeling threatened are in a better position to facilitate creative performance, hence, encourage them to always come up with original and novel ideas.

Hypothesis 1: AL positively affects employee creative behavior.

\section{Personal mastery (PM)}

Research on creativity initially focused on personality, attributes, knowledge, experience, and cognitive processes. Like any ability, creativity can be learned but without a guarantee of success (Amabile 1996). One predicament in this respect is the spontaneous nature of creativity, which makes it difficult to train for (Williams and Yang 1998). Research based on personal dispositions has explored creative ability from many viewpoints as discussed above. However, other personality attributes are worth exploring (Amabile et al. 1994). Like motivational disposition, PM is a trait that is selfreferent and an approach-oriented construct primarily concerned with task mastery and self-improvement. PM orientation is characterized by the desire to learn and improve one's competence, acquire new skills and knowledge, and use these to improve task performance (Kanfer and Heggestad 1997). Individuals with high PM orientation tend to look for opportunities to increase their knowledge (Heggestad and Kanfer 2000). It consists of a self-regulation process where an individual acts in a particular manner because of his or her personality (trait) inclinations. As a result, the individual exhibits more self-improvement predisposition, sets difficult goals, and selects challenging tasks for himself or herself (Heggestad and Kanfer 2000). Individuals with PM orientation can be more capable of indulging in creative behavior because of enhanced knowledge as a result of their learning efforts. Increase in knowledge and experience brings about a more comprehensive concentration of information, which is a necessary condition for creativity (Gong et al. 2012). The linkage between PM orientation and employee creative behavior can provide insight into factors that enhance employee creativity other than personality traits. This study is among the first to explore the relationship between PM and employee creativity. Positing that individuals rated high on PM are capable of generating multiple and novel responses to a problem that requires a novel approach for a solution, we hypothesize the following: 
Hypothesis 2: PM positively affects employee creative behavior.

\section{Autonomous motivation (AM)}

The componential theory of creativity (Amabile 1988) posits that three types of resources are required for enhancing an employee's creative behavior: (1) domain-specific knowledge, (2) creativity-related skills, and (3) motivation. Motivation is the key ingredient; it is the driver required for inducing creativity (Amabile 1988). There is much debate about the most appropriate type of motivation required for enhancing creativity, whether it is intrinsic or extrinsic. However, SDT proposes a unique type of motivation, that is, a combination of extrinsic and internalized extrinsic motivation; and it is produced as a result of basic psychological need satisfaction (Ryan and Deci 2000), named AM. AM is better in quality and is particularly useful when an individual indulges in heuristic activities such as creativity (Gagné and Deci 2005). The behavior exhibited as a result of AM does not have its origin in external pressure; it is produced by individual choice and volition. Previous studies have positively linked AM with the creative performance of Chinese school children (Ren et al. 2017). We expect these findings to hold ground in organizational settings. Furthermore, AM can serve as the process variable between various independent and outcome variables (Deci et al. 2017).

Moreover, AL theory is based on individual self-actualization (Walumbwa et al. 2008). An individual can be authentic only if he or she is free from any outside pressure or pursuits. SDT and the AL theory have a fair amount of overlapping (Miniotaite and Buciuniene 2013); for an act to be authentic, it must to be chosen by the self. This is similar to autonomous regulation which is a manifestation of the volitional self. The central premise of the relation between authentic leaders and their followers is that authentic leaders utilize self-awareness, self-regulation, and positive psychological states to garner authenticity in their followers. As a result, authentic leaders and their followers are in a cognitive symmetry; the leaders allow the followers to act with greater autonomy and volition (Avolio and Gardner 2005). This is akin to autonomous regulation. Research has also shown that leadership influences follower motivation (Hirst et al. 2009). Moreover, AL is associated with followers' need satisfaction, which ultimately leads to AM (Leroy et al. 2015). Building on these arguments, we posit that the relationship between $\mathrm{AL}$ and creative behavior is mediated by AM.

Individuals who have high levels of PM always strive to enhance their knowledge, skills, and abilities. They are hard-working, resolute, and achievement-oriented, and they seek challenging goals. The influence of PM orientation is similar to the need for competence under SDT, where an individual feels the urge to learn new skills and knowledge. Learning has long been associated with an internal locus of control (Rotter 1966). Individuals who are keen on learning have their actions originating from within themselves. Encouragement for learning comes from volition, not from any external control. Internal locus of control is necessary for an individual to feel a sense of autonomy (Waller 2002), and the foci for creativity is internal. Selforiginating actions for enhancing one's competency are, in a way, congruent with autonomous regulation. An individual who is yearning to learn autonomously acts with his or her own free will. Therefore, we posit that individuals with high PM are necessarily autonomously acting and are likely to exhibit creative behavior. Thus, we hypothesize the following:

Hypothesis 3: AM positively affects employee creative behavior.

Hypothesis 4: AL positively affects AM. 
Hypothesis 5: PM positively affects AM.

Hypothesis 6: AM mediates the relationship between $A L$ and employee creative behavior.

Hypothesis 7: AM mediates the relationship between PM and employee creative behavior.

\section{Method}

\section{Participants and procedure}

The target population for this study were employees of the software houses (software companies) in the cities of Lahore, Islamabad, Karachi, and Faisalabad in Pakistan. A total of 344 samples was collected using an online survey method with the Google Forms. We chose the software industry workers, because jobs in the software development industry are complex and require continuous creativity and innovation to survive (Edison et al. 2013). Only full-time workers of the registered software companies affiliated with the Pakistan Software Houses Association were included in the study population. We contacted the respondents via personal contacts and HR departments of the selected organizations. We used convenience sampling, a non-probability sampling technique. In situations where the sampling frame is not available, convenience sampling can be used (Hulland et al. 2018).

Data were collected from a single rater. We asked the respondents to rate themselves on a creative behavior scale. Self-rated creative behavior is valid, because employees are aware of the subtle tasks they perform on the job, which gives them a better position to rate themselves on creative behavior (Shalley et al. 2009). Self-rating of creativity has shown convergent, divergent, and predictive validity, and a growing body of research is showing that self-rated creativity is consistent with objective measures of creativity (Hughes et al. 2013). Addressing the concern for common method variance (CMV), if CMV is adequately taken care of, then, self-rated creativity can produce valid results (Ng and Feldman 2012). To address the concern for CMV, we used the marker variable technique. The marker variable technique is more effective than other post-hoc CMV detection methods (Malhotra et al. 2006). We selected a theoretically unrelated construct, "blue attitude" by Simmering et al. (2015) and incorporated it in the measurement scale at the time of data collection. Additionally, we used different rating scales for the dependent variable and the independent variable to create a psychological barrier based on Podsakoff et al. (2003) recommendations.

\section{Instruments}

Creativity was measured using self-reporting on a creative performance scale developed by Tierney et al. (1999). Nine-items of the scale $(\alpha=0.94)$ were used to rate creative behavior on a five-point Likert type scale. Two sample items are: (1) "demonstrated originality in his or her work," and (2) "took risk in terms of producing new ideas on the job."

$A M$ was assessed using a six-item multidimensional work motivation scale (MWMS; Gagné et al. 2015; $\alpha=0.94)$. Two sub-scales from the MWMS scale, namely, identified regulation and intrinsic regulation, were assessed with three-items each. AM was measured using a seven-point Likert type scale, as a unidimensional latent construct. Two sample items are: (1) "because I personally consider it important to put effort in this job," and (2) "because putting effort in this job aligns with my personal values."

$A L$, as a higher-order construct with four dimensions, was measured using a fourteen-item scale for Authentic Leadership Inventory (ALI; Neider and Schriesheim 
$2011 ; \alpha=0.87$ ). Each sub-scale of AL was measured using a five-point Likert type scale. Dimensions of AL, namely, self-awareness, relational transparency, internalized moral perspective, and balanced processing were measured using three, three, four, and four items, respectively. Two sample items are: (1) "My leader clearly states what he or she means," and (2) "My leader openly shares information with others."

$P M$ was computed as a higher-order construct with the Motivational Trait Questionnaire (MTQ; Kanfer and Ackerman 2000) using 16 items. Alcover and Topa (2018) reported a Cronbach's alpha of $\alpha=0.89$ for MTQ. Two dimensions of PM, namely, desire to learn and mastery goals, were measured, using eight-items for each. A five-point Likert type scale was used. Sample items are: (1) "When I become interested in a task, I try to learn as much about it as I can," and (2) "When I am learning something new, I try to completely understand it."

Demographic variables such as gender, age, years of experience, and education level were gathered from respondents. Previous studies have shown that level of education and job experience can serve as a facilitator of creativity (Amabile 1988; Tierney and Farmer 2002). Therefore, these demographic variables were used as control variables.

Marker variable was assessed using the "blue attitude" (Simmering et al. 2015) scale with three items: "I like the color blue," "I prefer blue to other colors," and "I like blue cloths."

\section{Data analysis}

We used structural equational modelling (SEM) for data analysis. The model of the study is prediction oriented. In prediction-oriented scenarios, the partial least squares (PLS) SEM is appropriate for data analysis (Hair et al. 2018). PLS-SEM is a variance-based technique suitable for both composite and factors, and when dealing with prediction-oriented complex study models with relaxed data and specification demands (Henseler 2017). When used with a robust theoretical backdrop, PLS-SEM can effectively compete with Covariance based (CB)-SEM (Chin 1998). Furthermore, when the purpose of the study is to determine the key predictors of a target construct, or exploration or extension of theoretical structures, PLS-SEM is the tool of choice (Hair et al. 2014a, 2014b). PLS-SEM is a valid method for data analysis in the human resources management (HRM) discipline (Ringle et al. 2020). We used the SmartPLS 3.2.2 software package for studying factor structure, construct structure, and hypothesis testing.

\section{Results}

\section{Descriptive}

We performed descriptive statistics using the software package IBM SPSS (version 25). The total sample size was $N=344$, out of which $86.9 \%$ of respondents are male, and $13.1 \%$ are female, which is lower than the average female participation (i.e., 25\%) in the Pakistani workforce (World Bank 2019). Furthermore, 29.1\% of the respondents were between the ages of $20-25,47.1 \%$ between 26 and 30, 14.7\% between 31 and 35, and 9.1\% were above 35 years of age. The majority of the respondents had a bachelor's degree $(61.2 \%)$, followed by a master's degree $(34.3 \%), 1.8 \%$ intermediate, $1.5 \% \mathrm{PhD}$, and $1.2 \%$ other degrees. Those with less than 1 year of experience comprised 9.3\%; 31.8\% had between 1 to 3 years; 23.2\% had between 4 to 5 years; $15.5 \%$ had between 6 to 8 years; and $20.2 \%$ had more than 35 years of experience. Table 1 presents the descriptive statistics; presentation of descriptive statistics is a good practice (Hair et al. 2017). 


\section{Measurement model}

AL was theorized as a reflective-reflective higher-order construct. AL has a confirmed multidimensional structure; however, its dimensions theoretically overlap (Levesque-Côté et al. 2018). Hence, it is theorized as a reflective-reflective multidimensional construct. $\mathrm{PM}$ is also theorized as a reflective-reflective higher-order construct. Creativity and motivation are theorized as unidimensional first-order constructs. We used the repeated indicator approach to assess reflective-reflective higher-order constructs (Sarstedt et al. 2019).

Reliability metrics (i.e., Cronbach alpha, $\alpha \geq 0.70$; Composite Reliability, $\mathrm{CR} \geq 0.70$ ) were satisfactory, as $\alpha$ and CR for all the constructs were above 0.70 . Convergent validity was examined using item/indicator loading and average variance extracted (AVE). The values of AVE for all the constructs ranged between 0.504 to 0.938 , hence, deemed satisfactory as per criteria (e.g., > 0.50, Ringle et al. 2014). For the indicator loading analysis, the criterion is that for all the indicators to be retained, indicator loadings should be at least 0.708 (Hair et al. 2020); however, the indicators till the value of 0.60 can be retained if AVE is above 0.50 (Ramayah et al. 2016). One indicator with a loading of CR4 $=0.611$ was removed from the creativity construct to improve the AVE of the construct. Two indicators from the mastery goal dimension of PM were removed, because they had a loading below 0.60 (PM10 = 0.074; PM15 = - 0.203). The rest of the indicators had values above the threshold of 0.60 , ranging between 0.601 and 0.933. Similarly, for reflective-reflective higher-order constructs, CR and AVE were above the desirable level (i.e., AL: $\mathrm{CR}=0.790$, AVE = 0.938; PM: $\mathrm{CR}=0.927$, AVE = 0.865). Complete details of the measurement model are included in Tables 3 and 4 in Appendix.

\section{Discriminant validity}

Discriminant validity is defined as "the extent to which the construct under investigation is distinct from other constructs" (Campbell and Fiske 1959). Discriminant validity is established when shared variance within the construct is higher than the shared variance between the constructs of the statistical model (Hair et al. 2020). We tested discriminant validity using two metrics: FornellLacker (Fornell and Larcker 1981) and Hetrotrait-Monotrait (HTMT) (Henseler et al. 2015).

Table 1 shows that the square roots of AVE of each construct (in bold) are higher than the inter-correlation of the constructs, indicating discriminant validity according to Fornell and Larcker (1981) criteria. Furthermore, HTMT calculations for all the values are above the criteria (e.g., > 0.85: Henseler et al. 2015), and bias-corrected confidence intervals do not straddle the value of 1 between the confidence intervals, providing additional evidence of discriminant validity (Ramayah et al. 2016). Therefore, discriminant validity is established. Detailed HTMT results are presented in Tables 3 and 4 in Appendix.

Table 1 Descriptive statistics

\begin{tabular}{lllllll}
\hline & Mean & SD & $\mathbf{1}$ & $\mathbf{2}$ & $\mathbf{3}$ & $\mathbf{4}$ \\
\hline Creativity & 3.77 & 0.61 & $\mathbf{0 . 7 1}$ & & & \\
Autonomous motivation & 5.27 & 1.05 & $0.55^{* *}$ & $\mathbf{0 . 8 2}$ & & \\
Authentic leadership & 3.69 & 0.70 & $0.42^{* *}$ & $0.48^{* *}$ & $\mathbf{0 . 8 8}$ & \\
Personal mastery & 3.95 & 0.48 & $0.48^{* *}$ & $0.55^{* *}$ & $0.46^{* *}$ & $\mathbf{0 . 9 3}$ \\
\hline
\end{tabular}

Notes. $N=344 . \mathrm{SD}$ is standard deviation. The matrix represents the two-tailed Pearson Bivariate Correlation. Correlation is significant at ${ }^{* *} p<0.01$. Square Root of Average Variance Extracted (SQRT-AVE) is shown in bold on the diagonal line. Other entries stand for the correlations between variables 


\section{Common method variance (CMV)}

Data collected from a single source can be prone to common method bias (Podsakoff et al. 2010). We used a marker variable technique to test whether CMV is present. We employed "blue attitude" and used a marker variable technique according to (Rönkkö and Ylitalo 2011). There was no significant difference between the baseline model and the model where marker variable was regressed on both endogenous constructs of the study. Moreover, the $R^{2}$ change observed in AM and creativity was 0.02 and 0.00 , respectively, which is not significant. Therefore, it can be assumed that the results are not affected by CMV.

\section{Control variables and multi-collinearity}

\section{Structural model}

Structural model path coefficients were statistically significant and positive. Values of the path coefficients were within the range of +1 and -1 . A path coefficient value that is closer to +1 indicates a strong positive relationship between variables. Coefficient of determination or $R^{2}$ represents the total variance caused in the endogenous variable by the exogenous variables of the model combined (Chin 1998). A general rule of thumb for interpreting the value of $R^{2}$ is $R^{2} \geq 0.19=$ weak, $R^{2} \geq 033=$ moderate, and $R^{2} \geq 0.67=$ substantial. $R^{2}$ for employee creative behavior was $R^{2}=0.359$, which indicates a moderate level of strength. Moreover, the results for the structural model presented in Table 2 show that the theorized model is significant and meaningful (Fig. 1).

Additionally, the values of Stone-Geisser's test (Q2) was Q2 $=0.236$ for creative behavior and Q2 $=0.165$ for autonomous motivation. Both Q2 values are above 0 , signifying the predictive relevance of the model (Hair et al. 2014a). Other hypothesized direct relationships in the study, namely, between $\mathrm{AL}$ and creative behavior $(\mathrm{AL} \rightarrow \mathrm{CR}: \beta=0.170 ; p=$ $0.001 ; t=2.588$; 95\%), PM (PM $\rightarrow \mathrm{CR}: \beta=0.200 ; p=0.001 ; t=3.131 ; 95 \%)$, AM and creative behavior $(\mathrm{AM} \rightarrow \mathrm{CR}: \beta=0.345 ; p=0.001 ; t=5.513 ; 95 \%), \mathrm{AL}$ and $\mathrm{AM}(\mathrm{AL} \rightarrow \mathrm{AM}$ : $\beta=0.287 ; p=0.001 ; t=5.271 ; 95 \%), \mathrm{PM}$ and AM (PM $\rightarrow$ AM: $\beta=0.445 ; p=0.001 ; t=$ 9.153; 95\%), are statistically significant and meaningful, thus, supported.

Hypothesized indirect relationships are also significant and supported. The relationship between $\mathrm{AL}$ and creative behavior is mediated by $\mathrm{AM}(\mathrm{AL} \rightarrow \mathrm{AM} \rightarrow \mathrm{CR}: \beta=0.099$; $p=0.001 ; t=3.532 ; 95 \%)$, and the relationship between $\mathrm{PM}$ and creative behavior is also mediated by $\mathrm{AM}(\mathrm{PM} \rightarrow \mathrm{AM} \rightarrow \mathrm{CR}: \beta=0.154 ; p=0.001 ; t=4.790 ; 95 \%)$.

\section{Discussion}

Employee creative behavior is the product of complex interactions between individuals and their environments, influenced by variables within and outside the individual (Woodman et al. 1993). The current study investigates the influences of individual difference, namely, PM and leadership type, authentic leadership in the organizational environment, on employee creativity, as well as their relative contribution towards the said phenomenon. Leadership is the most important factor that can influence employee creative behavior in an organizational environment (Hughes et al. 2018). However, an individual's ability to generate creative ideas, which is influenced by individual differences, is also of paramount importance (Amabile 1996).

Our study results indicate that AL and personal mastery have a direct relationship with employee creative behavior, through the motivational mechanism of autonomous 
Table 2 Hypotheses

\begin{tabular}{lllllllllll}
\hline & Relationship & B & SE & $\boldsymbol{t}$-value & Cl-LL & Cl-UL & Decision & $\boldsymbol{f}^{2}$ & $\boldsymbol{R}^{\mathbf{2}}$ & Q2 \\
\hline $\mathrm{H} 1$ & $\mathrm{AL} \rightarrow \mathrm{CR}$ & 0.170 & 0.066 & 2.588 & 0.044 & 0.392 & Accepted & 0.032 & 0.359 & 0.236 \\
$\mathrm{H} 2$ & $\mathrm{PM} \rightarrow \mathrm{CR}$ & 0.200 & 0.064 & 3.131 & 0.069 & 0.318 & Accepted & 0.039 & - & - \\
$\mathrm{H} 3$ & $\mathrm{AM} \rightarrow \mathrm{CR}$ & 0.345 & 0.063 & 5.513 & 0.226 & 0.468 & Accepted & 0.107 & - & - \\
$\mathrm{H} 4$ & $\mathrm{AL} \rightarrow \mathrm{AM}$ & 0.287 & 0.054 & 5.271 & 0.177 & 0.392 & Accepted & 0.112 & 0.399 & 0.165 \\
$\mathrm{H} 5$ & $\mathrm{PM} \rightarrow \mathrm{AM}$ & 0.445 & 0.049 & 9.153 & 0.354 & 0.540 & Accepted & 0.258 & - & - \\
$\mathrm{H} 6$ & $\mathrm{AL} \rightarrow \mathrm{AM} \rightarrow \mathrm{CR}$ & 0.099 & 0.028 & 3.532 & 0.051 & 0.159 & Accepted & - & - & - \\
$\mathrm{H} 7$ & $\mathrm{PM} \rightarrow \mathrm{AM} \rightarrow \mathrm{CR}$ & 0.154 & 0.032 & 4.790 & 0.096 & 0.223 & Accepted & - & - & - \\
\hline
\end{tabular}

Notes. Results are the output of the Two-Tailed Bias Corrected and Accelerated Complete Bootstrapping with 2000 subsamples at the 0.05 significance level

$A L=$ authentic leadership, $A M=$ autonomous motivation, $C R=$ employee creative behavior, $P M=$ personal mastery

motivation. Our findings are in line with that of the previous studies and confirm the relationship between AL and employee creative behavior (e.g., Chaudhary and Panda 2018; Rego et al. 2014). To the best of our knowledge, there was no study linking PM as a motivational orientation with employee creative behavior, and this is the first study exploring the role of motivational orientation, and its predictability, on employee creative behavior. The study results show that PM has a direct relationship with creative behavior. These findings are in line with other studies carried out on similar constructs such as learning goal orientation (e.g., Huang and Luthans 2015), as both of the constructs belong to the approach motivation complex. Besides, both AL and PM orientation predict creative behavior through AM. This mechanism has seldom been explored. AM was found to be a significant mediator between AL and creative behavior, and PM and creative behavior. One implication of this finding is that the mechanism tested in the study assimilates the creativity literature and SDT. This study presents a new mechanism for predicting employee creative behavior based on SDT. Another implication for testing AM as a mechanism for creative behavior is that it provides evidence of the importance of internalized extrinsic motivation. The synergetic effect of extrinsic motivation and intrinsic motivation has been seldom tested. Moreover, the study results suggest that, as a predictor of employee creativity, AM performs better than both AL and PM.

Moreover, in this study, we tested individual and work-related factors for their combined and relative contributions towards predicting employee creative behavior. The findings suggest that

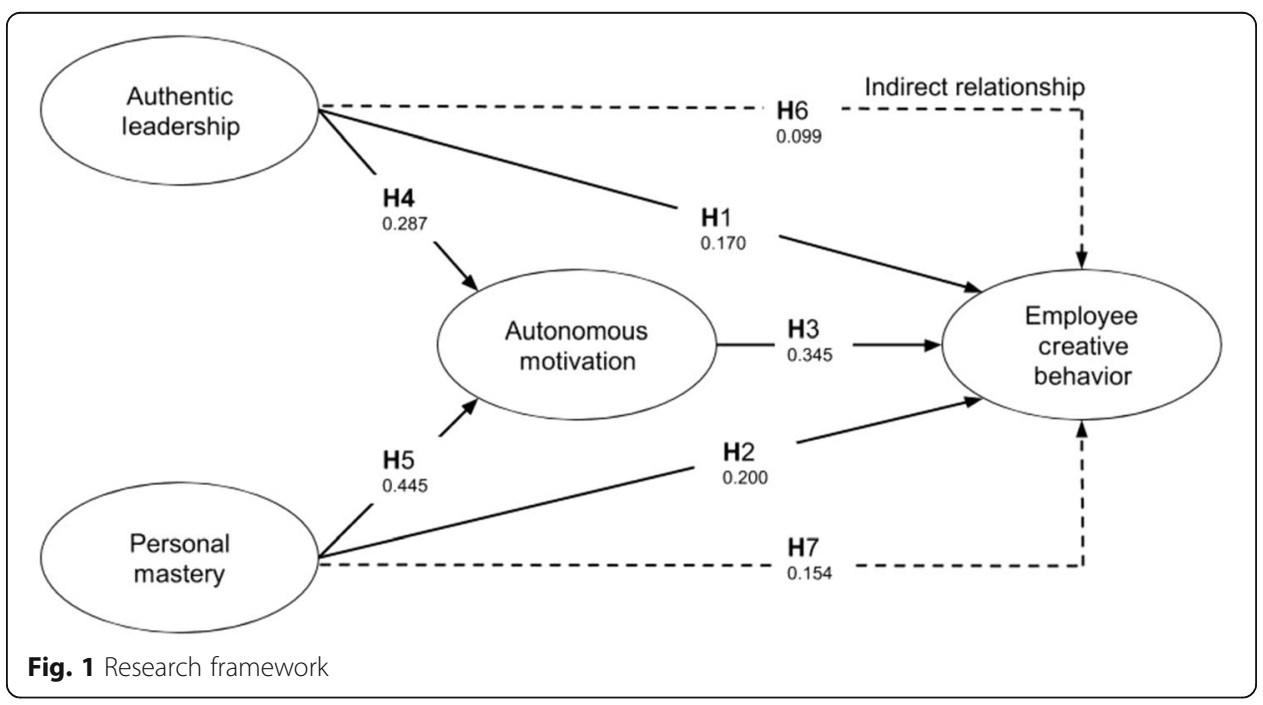


$\mathrm{AL}$ and PM orientation moderately predict creative behavior through autonomous motivation. The individual contribution of AL is almost half of that of PM orientation. This shows that motivational orientation contributes to employee creative behavior more than the influence of leadership. This finding reinforces the argument that creativity is a phenomenon that originates in the individual (Soriano de Alencar 2012). However, the facilitating role of environmental factors can play a pulling role, and the impetus for creative endeavor originates from within.

\section{Implications for research and practice}

Creativity research in the business domain is gaining increasing importance. In comparison to its rich background in other fields of study such as education and the arts, creativity research in the business field is limited. The tradition of exploring the environment for creative cues rather than personality and individual differences is recent, and the combination of environmental factors with individual dispositions when studying employee creativity is even rarer. Our study provides a piece of evidence that personality dispositions and environmental factors synergistically perform in enhancing employee creative behavior. It also confirms that the selfdetermination perspective of employee creative behavior can play an important role in correctly using extrinsic motivation to complement intrinsic motivation.

However, individual personality dispositions are shown to have more importance than leadership, an external environmental factor. Thus, when recruiting for a creative workforce, human resources practitioners can look for a particular trait-set that would enable organizations to benefit in future creative endeavors. Although the impact of AL is less than that of PM orientation, leaders who root their behavior in authenticity can bolster creative behavior among their workforce.

\section{Limitation and future research}

This study has a cross-sectional design and is based on data obtained from a single source, which can result in common method bias and causal limitations when examining mediation. Although we have tried to deploy mechanisms for dealing with the common method bias and reported that the results are pointing towards the absence of common method bias, singlesource data are not very desirable for robust research findings. For future research, we recommend data to be obtained from multiple sources, both objective and subjective, testing the convergence of objective creative achievements with subjective perceptions.

Another limitation of the study involves mediation and causal claims using a cross-sectional research design. We have refrained from making hardcore causal claims based on the research model, as the study is mainly prediction (not causality) oriented. We suggest a longitudinal research design to cement the findings of the current study or perhaps diary studies for making strong causal claims based on the research model. Finally, this study tested one individual difference and one environmental factor's role in fostering creative behavior. We suggest that, for future research, elements from job design should be used in combination with individual differences and other environmental factors to determine their combined and relative importance in fostering employee creative behavior. The individual difference used in this study belongs to the approach motivation complex that is similar to learning goal orientation and has a positive predictive relevance with creative behavior. It would be interesting to test if avoidance motivation has a detrimental effect on creative behavior, as some level of stress has been shown to have a positive relationship with employee creative behavior. 


\section{Appendix}

Table 3 Measurement model

\begin{tabular}{|c|c|c|c|c|c|c|}
\hline Construct (2nd order) & Dimensions & Items & Loading & Cronbach alpha $(a)$ & CR & AVE \\
\hline \multirow[t]{8}{*}{ Creativity } & & CR1 & 0.721 & 0.859 & 0.890 & 0.504 \\
\hline & & CR2 & 0.691 & & & \\
\hline & & CR3 & 0.675 & & & \\
\hline & & CR5 & 0.657 & & & \\
\hline & & CR6 & 0.735 & & & \\
\hline & & CR7 & 0.750 & & & \\
\hline & & CR8 & 0.750 & & & \\
\hline & & CR9 & 0.697 & & & \\
\hline \multirow[t]{6}{*}{ Autonomous motivation } & & AU1 & 0.778 & 0.889 & 0.915 & 0.643 \\
\hline & & AU2 & 0.797 & & & \\
\hline & & AU3 & 0.776 & & & \\
\hline & & $\mathrm{A} \cup 4$ & 0.786 & & & \\
\hline & & AU5 & 0.839 & & & \\
\hline & & AU6 & 0.835 & & & \\
\hline \multirow[t]{19}{*}{ Authentic leadership } & & Bal-Proc & 0.900 & & & \\
\hline & & Int-Mora & 0.875 & - & 0.790 & 0.938 \\
\hline & & Rel-Trans & 0.904 & & & \\
\hline & & Self-Awar & 0.875 & & & \\
\hline & BP & AL1 & 0.842 & 0.815 & 0.890 & 0.730 \\
\hline & & AL2 & 0.829 & & & \\
\hline & & AL3 & 0.892 & & & \\
\hline & IMP & AL4 & 0.838 & 0.811 & 0.888 & 0.726 \\
\hline & & AL5 & 0.874 & & & \\
\hline & & AL6 & 0.834 & & & \\
\hline & RT & AL7 & 0.704 & 0.819 & 0.881 & 0.650 \\
\hline & & AL8 & 0.827 & & & \\
\hline & & AL9 & 0.814 & & & \\
\hline & & AL10 & 0.870 & & & \\
\hline & SA & & & & & \\
\hline & & AL11 & 0.850 & 0.823 & 0.889 & 0.666 \\
\hline & & AL12 & 0.814 & & & \\
\hline & & AL13 & 0.825 & & & \\
\hline & & AL14 & 0.774 & & & \\
\hline \multirow[t]{7}{*}{ Personal mastery } & & Des-Lear & 0.927 & - & & \\
\hline & & Mas-Goal & 0.933 & & 0.927 & 0.865 \\
\hline & $\mathrm{DL}$ & PM1 & 0.741 & 0.891 & 0.913 & 0.569 \\
\hline & & PM2 & 0.748 & & & \\
\hline & & PM3 & 0.747 & & & \\
\hline & & PM4 & 0.803 & & & \\
\hline & & PM5 & 0.650 & & & \\
\hline
\end{tabular}


Table 3 Measurement model (Continued)

\begin{tabular}{|c|c|c|c|c|c|c|}
\hline Construct (2nd order) & Dimensions & Items & Loading & Cronbach alpha $(a)$ & CR & AVE \\
\hline & \multirow{9}{*}{ MG } & PM6 & 0.797 & \multirow{9}{*}{0.873} & \multirow{9}{*}{0.905} & \multirow{9}{*}{0.617} \\
\hline & & PM7 & 0.796 & & & \\
\hline & & PM8 & 0.739 & & & \\
\hline & & PM9 & 0.823 & & & \\
\hline & & PM11 & 0.842 & & & \\
\hline & & PM12 & 0.849 & & & \\
\hline & & PM13 & 0.801 & & & \\
\hline & & PM15 & 0.601 & & & \\
\hline & & PM16 & 0.772 & & & \\
\hline
\end{tabular}

Notes. $B P=$ balanced processing, $D L=$ desire to learn, $I M P=$ internal moral perspective, $M G=$ mastery goals, $R T=$ relational transparency, $S A=$ self-awareness

Table 4 HTMT results

\begin{tabular}{|c|c|c|c|c|}
\hline & $A L$ & $A M$ & CR & PM \\
\hline \multicolumn{5}{|l|}{$\mathrm{AL}$} \\
\hline AM & $\mathbf{0 . 5 4}(0.426,0.641)$ & & & \\
\hline CR & $\mathbf{0 . 4 8 6}(0.352,0.601)$ & $\mathbf{0 . 6 1 6}(0.500,0.718)$ & & \\
\hline PM & $\mathbf{0 . 5 2 9}(0.402,0.647)$ & $\mathbf{0 . 6 6 4}(0.564,0.743)$ & $\mathbf{0 . 5 5 7}(0.426,0.663)$ & \\
\hline
\end{tabular}

Notes. Parentheses represents bootstrapped bias-corrected $95 \%$ confidence interval (LL, UL) at 0.05 significance level, All values in bold represent HTMT ratio of correlations $(<0.85)$

$A L=$ authentic leadership, $A M=$ autonomous motivation, $C R=$ employee creative behavior, $P M=$ personal mastery

Acknowledgements

We thank the participants of the study who responded with utmost kindness and care.

Authors' contributions

All the authors have contributed equally to the study. The author(s) read and approved the final manuscript.

Funding

No applicable.

Availability of data and materials

The data collected and analyzed during this study is available from the University of Malaya data repository, and its availability depends on the clearance from the said institution. For this study, adequate ethical clearance was obtained from the ethical clearance committee of the University of Malaya to ensure the privacy of the respondents.

\section{Competing interests}

The authors of the study declare that they have no conflict of interest whatsoever with the subject matter of the study.

\section{Author details}

${ }^{1}$ University of Malaya, Kuala Lumpur, Malaysia. ²Jiangsu University, Zhenjiang, Jiangsu, China.

Received: 18 June 2020 Accepted: 13 January 2021

Published online: 19 March 2021

References

Afsar, B., \& Umrani, W. A. (2020). Transformational leadership and innovative work behavior: The role of motivation to learn, task complexity and innovation climate. European Journal of Innovation Management, 23(3), 402-428.

Alcover, C. M., \& Topa, G. (2018). Work characteristics, motivational orientations, psychological work ability, and job mobility intentions of older workers. PLoS One, 13(4), e0195973.

Amabile, T. M. (1983). The social psychology of creativity. New York: Springer-Verlag.

Amabile, T. M. (1988). A model of creativity and innovation in organizations. In B. S. Cummings (Ed.), Research in organizational behavior, (vol. 10, pp. 123-167). Greenwich: JAl Press.

Amabile, T. M. (1996). Creativity in context: Update to the social psychology of creativity. London: Hachette UK. 
Amabile, T. M., Hill, K. G., Hennessey, B. A., \& Tighe, E. M. (1994). The work preference inventory: Assessing intrinsic and extrinsic motivational orientations. Journal of Personality and Social Psychology, 66(5), 950-967.

Amabile, T. M., \& Pratt, M. G. (2016). The dynamic componential model of creativity and innovation in organizations: Making progress, making meaning. Research in Organizational Behavior: An Annual Series of Analytical Essays and Critical Reviews, $36,157-183$.

Anderson, N., De Dreu, C. K. W., \& Nijstad, B. A. (2004). The routinization of innovation research: A constructively critical review of the state-of-the-science. Journal of Organizational Behavior, 25(2), 147-173.

Anderson, N., Potočnik, K., \& Zhou, J. (2014). Innovation and creativity in organizations: A state-of-the-science review, prospective commentary, and guiding framework. Journal of Management, 40(5), 1297-1333.

Avolio, B. J., \& Fred, O. W. (2014). Authentic leadership theory, research and practicesteps taken and steps that remain. In V. D. David (Ed.), The Oxford handbook of leadership and organizations. UK: Oxford University Press.

Avolio, B. J., \& Gardner, W. L. (2005). Authentic leadership development: Getting to the root of positive forms of leadership. Leadership Quarterly, 16(3), 315-338.

Avolio, B. J., Walumbwa, F. O., \& Weber, T. J. (2009). Leadership: Current theories, research, and future directions. Annual Review of Psychology, 60(1), 421-449.

Banks, G. C., McCauley, K. D., Gardner, W. L., \& Guler, C. E. (2016). A meta-analytic review of authentic and transformational leadership: A test for redundancy. The Leadership Quarterly, 27(4), 634-652.

Batey, M., \& Furnham, A. (2006). Creativity, intelligence, and personality: A critical review of the scattered literature. Genetic Social and General Psychology Monographs, 132(4), 355-429.

Brown, K. W., \& Ryan, R. M. (2015). Fostering healthy self-regulation from within and without: A self-determination theory perspective. In P. A. Linley, \& S. Joseph (Eds.), Positive psychology in practice, (pp. 105-124). New Jersey: Wiley.

Campbell, D. T., \& Fiske, D. W. (1959). Convergent and discriminant validation by the multitrait-multimethod matrix. Psychological Bulletin, 56(2), 81-105.

Černe, M., Jaklič, M., \& Škerlavaj, M. (2013). Authentic leadership, creativity, and innovation: A multilevel perspective. Leadership, 9(1), 63-85.

Chaudhary, R., \& Panda, C. (2018). Authentic leadership and creativity: The intervening role of psychological meaningfulness, safety and work engagement. International Journal of Productivity and Performance Management, 67(9), 2071-2088.

Chin, W. W. (1998). Commentary: Issues and opinion on structural equation modeling. MIS Quarterly, 22(1), vii-xvi.

Deci, E. L., Olafsen, A. H., \& Ryan, R. M. (2017). Self-determination theory in work organizations: The state of a science. Annual Review of Organizational Psychology and Organizational Behavior, 4(1), 19-43.

Deci, E. L., \& Ryan, R. M. (1985). Intrinsic motivation and self-determination in human behavior. New York: Springer.

Edison, H., Bin Ali, N., \& Torkar, R. (2013). Towards innovation measurement in the software industry. Journal of Systems and Software, 86(5), 1390-1407.

Eisenberger, R., \& Rhoades, L. (2001). Incremental effects of reward on creativity. Journal of Personality and Social Psychology, $81(4), 728-741$

Eisenberger, R., \& Shanock, L. (2003). Rewards, intrinsic motivation, and creativity: A case study of conceptual and methodological isolation. Creativity Research Journal, 15(2-3), 121-130.

Florida, R. (2010). The flight of the creative class: The new global competition for talent. New York: Harper Collins.

Fornell, C., \& Larcker, D. F. (1981). Evaluating structural equation models with unobservable variables and measurement error. Journal of Marketing Research, 18(1), 39-50.

Gagné, M., \& Deci, E. L. (2005). Self-determination theory and work motivation. Journal of Organizational Behavior, 26(4), 331362.

Gagné, M., Forest, J., Vansteenkiste, M., Crevier-Braud, L., van den Broeck, A., Aspeli, A. K., .. Westbye, C. (2015). The multidimensional work motivation scale: Validation evidence in seven languages and nine countries. European Journal of Work and Organizational Psychology, 24(2), 178-196.

Gardner, W. L., Avolio, B. J., Luthans, F., May, D. R., \& Walumbwa, F. (2005). "Can you see the real me?": A self-based model of authentic leader and follower development. The Leadership Quarterly, 16(3), 343-372.

Gerhart, B., \& Fang, M. Y. (2015). Pay, intrinsic motivation, extrinsic motivation, performance, and creativity in the workplace: Revisiting long-held beliefs. Annual Review of Organizational Psychology and Organizational Behavior, 2(1), 489-521.

Gong, Y., Kim, T. Y., Lee, D. R., \& Zhu, J. (2012). A multilevel model of team goal orientation, information exchange, and creativity. Academy of Management Journal, 56(3), 827-851.

Hair, J. F., Hollingsworth, C. L., Randolph, A. B., \& Chong, A. Y. L. (2017). An updated and expanded assessment of PLS-SEM in information systems research. Industrial Management \& Data Systems, 117(3), 442-458.

Hair, J. F., Howard, M. C., \& Nitzl, C. (2020). Assessing measurement model quality in PLS-SEM using confirmatory composite analysis. Journal of Business Research, 109, 101-110.

Hair, J. F., Hult, G. T. M., Ringle, C., \& Sarstedt, M. (2014a). A primer on partial least squares structural equation modeling (PLSSEM). California: Sage Publishing.

Hair, J. F., Risher, J. J., Sarstedt, M., \& Ringle, C. M. (2018). When to use and how to report the results of PLS-SEM. European Business Review, 31(1), 2-24.

Hair, J. F., Sarstedt, M., Hopkins, L., \& Kuppelwieser, V. (2014b). Partial least squares structural equation modeling (PLS-SEM): An emerging tool in business research. European Business Review, 26(2), 106-121.

Hammond, M. M., Neff, N. L., Farr, J. L., Schwall, A. R., \& Zhao, X. (2011). Predictors of individual-level innovation at work: A meta-analysis. Psychology of Aesthetics, Creativity, and the Arts, 5(1), 90-105.

Heggestad, E. D., \& Kanfer, R. (2000). Individual differences in trait motivation: Development of the motivational trait questionnaire. International Journal of Educational Research, 33(7), 751-776.

Henseler, J. (2017). Partial least squares path modeling. In P. Leefang, T. Bijmolt, \& K. Pauwels (Eds.), Advanced methods for modeling markets: International series in quantitative marketing, (pp. 361-381). Heidelberg: Springer.

Henseler, J., Ringle, C. M., \& Sarstedt, M. (2015). A new criterion for assessing discriminant validity in variance-based structural equation modeling. Journal of the Academy of Marketing Science, 43(1), 115-135.

Hirst, G., van Dick, R., \& van Knippenberg, D. (2009). A social identity perspective on leadership and employee creativity. Journal of Organizational Behavior, 30(7), 963-982. 
Hornberg, J., \& Reiter-Palmon, R. (2017). Creativity and the big five personality traits. In G. J. Feist, J. C. Kaufman, \& R. ReiterPalmon (Eds.), The Cambridge handbook of creativity and personality research, (pp. 275-293). Cambridge: Cambridge University Press.

Huang, L., \& Luthans, F. (2015). Toward better understanding of the learning goal orientation-creativity relationship: The role of positive psychological capital. Applied Psychology, 64(2), 444-472.

Hughes, D. J., Furnham, A., \& Batey, M. (2013). The structure and personality predictors of self-rated creativity. Thinking Skills and Creativity, 9, 76-84.

Hughes, D. J., Lee, A., Tian, A. W., Newman, A., \& Legood, A. (2018). Leadership, creativity, and innovation: A critical review and practical recommendations. The Leadership Quarterly, 29(5), 549-569.

Hulland, J., Baumgartner, H., \& Smith, K. M. (2018). Marketing survey research best practices: Evidence and recommendations from a review of JAMS articles. Journal of the Academy of Marketing Science, 46(1), 92-108.

Kanfer, R., \& Ackerman, P. L. (2000). Individual differences in work motivation: Further explorations of a trait framework. Applied Psychology: An International Review, 49(3), 470-482.

Kanfer, R., \& Heggestad, E. D. (1997). Motivational traits and skills: A person-centered approach to work motivation. In L. L. Cummings, \& B. M. Staw (Eds.), Research in organizational behavior, (vol. 19, pp. 1-56). Greenwich: JAl, Press Inc..

Lehman, D. W., O'Connor, K., Kovács, B., \& Newman, G. E. (2018). Authenticity. Academy of Management Annals, 13(1), 1-42.

Leroy, H., Anseel, F., Gardner, W. L., \& Sels, L. (2015). Authentic leadership, authentic followership, basic need satisfaction, and work role performance: A cross-level study. Journal of Management, 41(6), 1677-1697.

Levesque-Côté, J., Fernet, C., Austin, S., \& Morin, A. J. S. (2018). New wine in a new bottle: Refining the assessment of authentic leadership using exploratory structural equation modeling (esem). Journal of Business and Psychology, 33(5), $611-628$.

Malhotra, N. K., Kim, S. S., \& Patil, A. (2006). Common method variance in IS research: A comparison of alternative approaches and a reanalysis of past research. Management Science, 52(12), 1865-1883.

Miniotaitè, A., \& Buciuniene, I. (2013). Explaining authentic leadership work outcomes from the perspective of selfdetermination theory. Management of Organizations: Systematic Research, 65, 63-75.

Neider, L. L., \& Schriesheim, C. A. (2011). The authentic leadership inventory (ALI): Development and empirical tests. Leadership Quarterly, 22(6), 1146-1164.

Ng, T. W. H., \& Feldman, D. C. (2012). A comparison of self-ratings and non-self-report measures of employee creativity. Human Relations, 65(8), 1021-1047.

Podsakoff, P., MacKenzie, S., \& Podsakoff, N. (2010). Sources of method bias in social science research and recommendations on how to control it. Annual Review of Psychology, 63, 539-569.

Podsakoff, P. M., MacKenzie, S. B., Lee, J.-Y., \& Podsakoff, N. P. (2003). Common method biases in behavioral research: A critical review of the literature and recommended remedies. Journal of Applied Psychology, 88(5), 879-903.

Puccio, G. J., \& Cabra, J. F. (2012). Idea generation and idea evaluation: Cognitive skills and deliberate practices. In M. D. Mumford (Ed.), Handbook of organizational creativity, (pp. 189-215). San Diego: Academic Press.

Ramayah, T., Hwa, C., Chuah, F., Ting, H., \& Memon, M. (2016). Partial least squares structural equation modeling (PLS-SEM) using smartpls 3.0: An updated and practical guide to statistical analysis. Kuala Lumpur: Pearson.

Rego, A., Sousa, F., Marques, C., \& Cunha, M. P. E. (2014). Hope and positive affect mediating the authentic leadership and creativity relationship. Journal of Business Research, 67(2), 200-210.

Ren, F., Li, Y., \& Zhang, J. (2017). Perceived parental control and Chinese middle school adolescents' creativity: The mediating role of autonomous motivation. Psychology of Aesthetics, Creativity, and the Arts, 11(1), 34-42.

Ringle, C. M., Sarstedt, M., Mitchell, R., \& Gudergan, S. P. (2020). Partial least squares structural equation modeling in HRM research. The International Journal of Human Resource Management, 31(12), 1617-1643.

Ringle, C. M., Silva, D., \& Bido, D. (2014). Structural equation modeling with the smartpls. Revista Brasileira de Marketing, 13(2), 56-73.

Rodríguez-Cifuentes, F., Segura-Camacho, A., García-Ael, C., \& Topa, G. (2020). The mediating role of psychological capital between motivational orientations and their organizational consequences. International Journal of Environmental Research and Public Health, 17(13), 4864.

Rönkkö, M., \& Ylitalo, J. (2011). PLS marker variable approach to diagnosing and controlling for method variance. In Paper presented at the international conference on information systems (ICIS), Shanghai, China.

Rotter, J. B. (1966). Generalized expectancies for internal versus external control of reinforcement. Psychological Monographs: General and Applied, 80(1), 1-28.

Ryan, R. M. (1982). Control and information in the intrapersonal sphere: An extension of cognitive evaluation theory. Journal of Personality and Social Psychology, 43(3), 450-461.

Ryan, R. M., \& Deci, E. L. (2000). Intrinsic and extrinsic motivations: Classic definitions and new directions. Contemporary Educational Psychology, 25(1), 54-67.

Ryan, R. M., \& Deci, E. L. (2019). Brick by brick: The origins, development, and future of self-determination theory. In A. J. Elliot (Ed.), Advances in motivation science, (vol. 6, pp. 111-156). Cambridge: Elsevier.

Ryan, R. M., Soenens, B., \& Vansteenkiste, M. (2019). Reflections on self-determination theory as an organizing framework for personality psychology: Interfaces, integrations, issues, and unfinished business. Journal of Personality, 87(1), 115-145.

Sarstedt, M., Hair, J. F., Cheah, J. H., Becker, J. M., \& Ringle, C. M. (2019). How to specify, estimate, and validate higher-order constructs in PLS-SEM. Australasian Marketing Journal (AMJ), 27(3), 197-211.

Selby, E. C., Shaw, E. J., \& Houtz, J. C. (2005). The creative personality. Gifted Child Quarterly, 49(4), 300-314.

Shafique, I., Ahmad, B., \& Kalyar Masood, N. (2019). How ethical leadership influences creativity and organizational innovation: Examining the underlying mechanisms. European Journal of Innovation Management, 23(1), 114-133.

Shalley, C. E., Gilson, L. L., \& Blum, T. C. (2009). Interactive effects of growth need strength, work context, and job complexity on self-reported creative performance. Academy of Management Journal, 52(3), 489-505.

Shen, W., Hommel, B., Yuan, Y., Chang, L., \& Zhang, W. (2018). Risk-taking and creativity: Convergent, but not divergent thinking is better in low-risk takers. Creativity Research Journal, 30(2), 224-231.

Simmering, M. J., Fuller, C. M., Richardson, H. A., Ocal, Y., \& Atinc, G. M. (2015). Marker variable choice, reporting, and interpretation in the detection of common method variance: A review and demonstration. Organizational Research Methods, 18(3), 473-511. 
Soriano de Alencar, E. M. L. (2012). Creativity in organizations: Facilitators and inhibitors. In M. D. Mumford (Ed.), Handbook of organizational creativity, (pp. 87-111). San Diego: Academic Press.

Tan, F. B., \& Leewongcharoen, K. (2005). Factors contributing to it industry success in developing countries: The case of Thailand. Information Technology for Development, 11(2), 161-194.

Tierney, P., \& Farmer, S. M. (2002). Creative self-efficacy: Its potential antecedents and relationship to creative performance. Academy of Management Journal, 45(6), 1137-1148.

Tierney, P., Farmer, S. M., \& Graen, G. B. (1999). An examination of leadership and employee creativity: The relevance of traits and relationships. Personnel Psychology, 52(3), 591-620

Waller, B. N. (2002). The psychological structure of patient autonomy. Cambridge Quarterly of Healthcare Ethics, 11(3), 257-265.

Walumbwa, F. O., Avolio, B. J., Gardner, W. L., Wernsing, T. S., \& Peterson, S. J. (2008). Authentic leadership: Development and validation of a theory-based measure. Journal of Management, 34(1), 89-126.

Williams, W. M., \& Yang, L. T. (1998). Organizational creativity. In R. J. Sternberg (Ed.), Handbook of creativity, (pp. 373-391). Cambridge: Cambridge University Press.

Woodman, R. W., Sawyer, J. E., \& Griffin, R. W. (1993). Toward a theory of organizational creativity. Academy of Management Review, 18(2), 293-321.

World Bank. (2019). Labor force participation rate, female (\% of female population ages 15+) (modeled ILO estimate)—Pakistan. Retrieved from https://bit.ly/2SPuyaa. Accessed, 5 May 2020.

Yang, J., Liu, H., \& Gu, J. (2017). A multi-level study of servant leadership on creativity: The roles of self-efficacy and power distance. Leadership \& Organization Development Journal, 38(5), 610-629.

\section{Publisher's Note}

Springer Nature remains neutral with regard to jurisdictional claims in published maps and institutional affiliations.

\section{Submit your manuscript to a SpringerOpen ${ }^{\circ}$ journal and benefit from:}

- Convenient online submission

- Rigorous peer review

- Open access: articles freely available online

- High visibility within the field

- Retaining the copyright to your article 